\title{
Upper Bound Analysis for Rectangular Shaped Sintered Metal Powder Preform Considering Homogeneous Pattern of Deformation
}

\author{
Parveen Kumar, R. K. Ranjan, and Rajive Kumar
}

\begin{abstract}
The paper reports on an investigation into the various aspects of high speed open die forging of $\mathrm{Cu}$ metal powder preforms, which have been compacted and sintered from atomized $\mathrm{Cu}$ metal powder. An attempt has been made for the determination of the relative average die pressure developed for given geometries of the disc during the open die forging of sintered metal powder preform by using an upper bound approach. The deformation characteristics of metal powder preform has been demonstrated by applying an appropriate interfacial friction law and yield criteria. The results so obtained are discussed critically to illustrate the interaction of various process parameters involved and are presented graphically. The deformation pattern is influenced by many factors which interact with each other,the main factors are the interfacial friction,initial density of the perform and the geometry of the perform. different frictional stresses are assumed on top and bottom interfaces of the die.
\end{abstract}

Index Terms - Interfacial friction, open die forging, sintered preform, upper bound method.

\section{INTRODUCTION}

Sinter metal forming technology is a rapidly developing near net shape mass production technology The final density of sinter formed products compares favorably with that of wrought products [1]-[2].We can get the product of desired properties by using the sintered perform Metal powder technology is creating interests in many parts of the world as the technology has extensive applications in the field of automobiles, aerospace, defense and other household products[3]-[5].This paper concerns the pressure distribution at the workpiece interface and die load during the cold forging of the disc at a particular speed, during the analysis an appropriate interfacial friction law and yield criterion for porous metal is used, as characteristics of porous materials during compression have to be taken into consideration. The densification and compression of sintered preform takes place simultaneously therefore volumetric constancy is not possible, as preform's density changes due to closing of inter particle pores. Thus, suitable yield criterion is required, which is dependent on relative density of perform. The high interfacial pressure, which is applied for deformation, breaks the die-work piece interfacial lubricant film therefore, we

Manuscript received August 1, 2012; revised September 20, 2012

P. Kumar is with the Department of Mathematics BRCM CET Bahal (Bhiwani) Haryana India (e-mail: parveen_brcm@ rediffmail.com).

R. K. Ranjan is with the Department of Mechanical Engineering Gyan Ganga ITS Jabalpur (M.P.) India (e-mail: rkranjanbit@gmail.com).

R. Kumar is with the Department of Mathematics DCRUST Sonipat Haryana India (e-mail: rajeev_kansal@yahoo.com). have to consider composite friction including both sliding and sticking friction [6]-[9].To analyze the deformation behavior of the sintered perform which helps to decide various parameters of the process in practical work and for industrial propose. Upper bound method approach seems to be the best appropriate technique as Upper bound method is better than the equilibrium method[12]. The results so obtained are discussed critically to illustrate the interaction of various parameters involved and.Friction condition are of the greatest importance. The relative velocity between the workpiece material and the die surface together with high interfacial pressure and/or deformation modes will create the conditions essential for a adhesion in addition to sliding. For such a mechanism of composite friction,the shear equation

$$
\tau=\mu\left[\mathrm{p}+\rho_{\mathrm{o}} \phi_{\mathrm{o}}\right]
$$

where the first term on the right is the sliding friction and the second is the friction due to adhesion, which is due to change of the relative density of the preform. The pattern of metal flow during the compression of a metal powder preform is such that there exists two zones, an inner one where no relative movement between workpiece and die occurs (the sticking zone), and an outer zone where sliding occurs. Therefore, the appropriate interfacial friction laws for different conditions given by Rooks [10] are :

$$
\tau=\mu\left[\mathbf{P}+\rho_{o} \phi_{o}\left\{1-\left(\frac{r_{m}-r}{n r_{0}}\right)\right\}\right]
$$

\section{UPPER BOUND APPROACH}

\section{A. Velocity Field}

$$
\begin{gathered}
U_{y}=\frac{(1-2 \eta)}{2(1+\eta)}\left[\frac{2 U}{h} y-\frac{2 U}{h} \alpha y\right] ; \\
U_{x}=\frac{2 U}{h} \alpha x ; \quad U_{z}=-\frac{2 U}{h} z
\end{gathered}
$$

B. Strain Rate

$$
\varepsilon_{x x}=\frac{2 U}{h} ; \varepsilon_{z z}=-\frac{2 U}{h} \alpha ; \varepsilon_{y y}=\frac{(1-2 \eta)}{2(1+\eta)} \frac{2 U}{h}-\frac{2 U}{h} \alpha
$$


C. Compressibility Equations for Powder Components

$$
\varepsilon_{x x}+\varepsilon_{y y}+\frac{1-2 \eta}{2(1+\eta)} \varepsilon_{z z}=0
$$

D. Deformation Energy

$$
\begin{aligned}
W_{d} & =\frac{2 \rho^{k} \sigma_{0}}{\sqrt{3}(1-2 \eta)} \int_{v}\left(\frac{1}{2}\left(\varepsilon_{x x}^{2}+\varepsilon_{y y}^{2}+\varepsilon_{z z}^{2}\right)\right)^{\frac{1}{2}} d v \\
W_{d} & =\frac{4 \rho^{k} \sigma_{0} U}{\sqrt{3}(1-2 \eta) h} \int_{v}\left(\alpha^{2}+\frac{(1-2 \eta)^{2}}{8(1+\eta)^{2}}-\frac{(1-2 \eta)}{2(1+\eta)} \alpha+\frac{1}{2}\right)^{\frac{1}{2}} d v \\
W_{d} & =\frac{w l \rho^{k} \sigma_{0} U}{2 \sqrt{3}(1-2 \eta)}\left(\alpha^{2}+\frac{1-2 \eta}{8(1+\eta)^{2}}-\frac{1-2 \eta}{2(1+\eta)} \alpha+\frac{1}{2}\right)^{\frac{1}{2}}
\end{aligned}
$$

Friction Power

$$
\begin{gathered}
W_{f}=\int_{v} \tau|\Delta v| d s ; \quad \Delta v=\left(U_{x}^{2}+U_{y}^{2}\right)^{\frac{1}{2}} \\
\Delta v=\frac{2 U}{h}\left[\alpha^{2} x^{2}+\frac{(1-2 \eta)^{2}}{4(1+\eta)^{2}}(1-\alpha)^{2} y^{2}\right]^{\frac{1}{2}} \\
W_{f}=\frac{2 U}{h} \tau \iint_{s}\left[\alpha^{2} x^{2}+\frac{(1-2 \eta)^{2}}{4(1+\eta)^{2}}(1-\alpha)^{2} y^{2}\right]^{\frac{1}{2}} d x d y
\end{gathered}
$$

E. Energy Dissipation Due To Inertia Force

$$
\mathrm{W}_{\mathrm{a}}=\frac{\rho_{\mathrm{p}}}{\mathrm{g}} \int_{\mathrm{v}} \mathrm{a}_{\mathrm{i}} \mathrm{U}_{\mathrm{i}} \mathrm{dv}
$$

$$
\begin{gathered}
=\frac{2 N \rho_{p}}{g} \int_{0}^{h w} \int_{0}^{l_{0}} \int_{0}\left(a_{x} U_{x}+a_{y} U_{y}+a_{z} U_{z}\right) d x \cdot d y \cdot d z \\
\mathrm{a}_{\mathrm{X}}=\mathrm{U}_{\mathrm{x}} \frac{\partial \mathrm{U}_{\mathrm{x}}}{\partial \mathrm{x}}+\mathrm{U}_{\mathrm{y}} \frac{\partial \mathrm{U}_{\mathrm{x}}}{\partial \mathrm{y}}+\mathrm{U}_{\mathrm{Z}} \frac{\partial \mathrm{U}_{\mathrm{X}}}{\partial \mathrm{z}}+\frac{\partial \mathrm{U}_{\mathrm{x}}}{\partial \mathrm{t}} \\
\mathrm{a}_{\mathrm{y}}=\mathrm{U}_{\mathrm{x}} \frac{\partial \mathrm{U}_{\mathrm{y}}}{\partial \mathrm{x}}+\mathrm{U}_{\mathrm{y}} \frac{\partial \mathrm{U}_{\mathrm{y}}}{\partial \mathrm{y}}+\mathrm{U}_{\mathrm{Z}} \frac{\partial \mathrm{U}_{\mathrm{Z}}}{\partial \mathrm{z}}+\frac{\partial \mathrm{U}_{\mathrm{y}}}{\partial \mathrm{t}} \\
\mathrm{a}_{\mathrm{Z}}=\mathrm{U}_{\mathrm{x}} \frac{\partial \mathrm{U}_{\mathrm{Z}}}{\partial \mathrm{x}}+\mathrm{U}_{\mathrm{y}} \frac{\partial \mathrm{U}_{\mathrm{Z}}}{\partial \mathrm{y}}+\mathrm{U}_{\mathrm{Z}} \frac{\partial \mathrm{U}_{\mathrm{Z}}}{\partial \mathrm{z}}+\frac{\partial \mathrm{U}_{\mathrm{Z}}}{\partial \mathrm{t}}
\end{gathered}
$$

$$
\frac{\partial U_{x}}{\partial x}=\frac{2 U}{h} \alpha \frac{\partial \mathrm{U}_{\mathrm{x}}}{\partial \mathrm{y}}=0
$$$$
\frac{\partial U_{x}}{\partial z}=0 ; \frac{\partial U_{x}}{\partial t}=\frac{2 \dot{U}}{h} \alpha x
$$

$$
\frac{\partial \mathrm{U}_{\mathrm{y}}}{\partial \mathrm{x}}=0 ; \frac{\partial U_{y}}{\partial y}=\frac{(1-2 \eta) 2 U}{2(1+\eta) h}-\frac{2 U}{h} \alpha ;
$$

$$
\begin{aligned}
& \frac{\partial U_{y}}{\partial z}=0 ; \frac{\partial U_{y}}{\partial t}=\frac{(1-2 \eta) 2 \dot{U} y}{2(1+\eta) h}-\frac{2 \dot{U}}{h} \alpha y \\
& \frac{\partial \mathrm{U}_{\mathrm{z}}}{\partial \mathrm{x}}=0 ; \quad \frac{\partial \mathrm{U}_{\mathrm{z}}}{\partial \mathrm{y}}=0 ; \quad \frac{\partial U_{z}}{\partial z}=-\frac{2 U}{h} ;
\end{aligned}
$$

Put these values in equation (4), we have,

$$
\begin{gathered}
a_{x}=\frac{4 U^{2} \cdot \alpha^{2} x}{h^{2}}+\frac{2 \dot{U} \alpha x}{h} ; \\
a_{x} U_{x}=\frac{8 U^{3} \cdot \alpha^{3} \cdot x^{2}}{h^{3}}+\frac{4 \dot{U} \dot{U} \cdot \alpha^{2} \cdot x^{2}}{h^{2}}
\end{gathered}
$$

$$
\begin{gathered}
a_{z}=\frac{4 U^{2} \cdot z}{h^{2}}-\frac{2 \dot{U}}{h} z \\
a_{z} U_{z}=-\frac{8 U^{3} z^{2}}{h^{3}}+\frac{4 \dot{U U} z^{2}}{h^{2}} \\
a_{y}=\frac{(1-2 \eta)^{2} 4 U^{2} \cdot y}{4(1+\eta)^{2} h^{2}}-2 \frac{(1-2 \eta) 4 U^{2} \alpha \cdot y}{2(1+\eta) h^{2}} \\
+\frac{4 U^{2} \alpha^{2} \cdot y}{h^{2}}+\frac{(1-2 \eta) \dot{U} \cdot y}{2(1+\eta) h}-\frac{2 \dot{U}}{h} \alpha \cdot y
\end{gathered}
$$

$$
\begin{aligned}
& a_{y} U_{y}=\left[\frac{(1-2 \eta)^{3} U^{3} \cdot y^{2}}{(1+\eta)^{3} h^{3}}+\frac{4(1-2 \eta)^{2} U^{3} \cdot \alpha y^{2}}{(1+\eta)^{2} h^{3}}\right. \\
& +\frac{4(1-2 \eta) U^{3} \cdot \alpha^{2} y^{2}}{(1+\eta) h^{3}}+\frac{(1-2 \eta)^{2} U \dot{U} \cdot y^{2}}{(1+\eta)^{2} h^{2}}- \\
& \left.\frac{2(1-2 \eta) U \dot{U} \alpha \cdot y^{2}}{(1+\eta) h^{2}}\right](1-\alpha)
\end{aligned}
$$

From equation (3), after integration we get-

$$
W_{a}=\frac{2 N \rho_{p}}{g}\left[\begin{array}{l}
\left\langle\frac{8 U^{3} \alpha}{h}+4 U \dot{U}\right\rangle \frac{w l^{3} \alpha^{2}}{3 h}+ \\
(1+\alpha)\left(\begin{array}{l}
\left(A^{3}-4 A^{2} \alpha+4 A \alpha^{2}\right) \frac{U^{3}}{h}+ \\
\left(A^{2}-2 A \alpha\right) U \dot{U}
\end{array}\right) \frac{w^{3}}{3 h}+ \\
\left\langle\begin{array}{l}
\left.\left(4 U \dot{U} h-8 U^{3}\right)\right\rangle \frac{l w}{3} \\
A=\frac{(1-2 \eta)}{(1+\eta)}
\end{array}\right.
\end{array}\right]
$$

\section{F. Die Load}

For plastic deformation, external power $\mathrm{J}$ is 


$$
\stackrel{*}{\mathrm{~J}}=\mathrm{W}_{\mathrm{i}}+\mathrm{W}_{\mathrm{f}}+\mathrm{W}_{\mathrm{a}}+\mathrm{W}_{\mathrm{t}}
$$

$\left(W_{i}\right)$ denotes therate of internal energy dissipation

$\left(W_{f}\right)$ denotes the frictional shear energy losses

$\left(W_{a}\right)$ denotes energy dissipation by inertia forces

$\left(W_{t}\right)$ covers the power supplied by body tractions.

In this case no external surface traction is stipulated.

Therefore,

$$
W_{t}=0 . \quad \stackrel{*}{\mathrm{~J}}=\int \mathrm{F}_{\mathrm{i}} \mathrm{U}_{\mathrm{i}} \mathrm{ds}=\mathrm{PU}
$$

Optimization of total power

$$
\begin{gathered}
J=W_{d}+W_{f}+W_{a} \text { Now, } p=\frac{P}{\left(\frac{w l}{4}\right)} ; \text { for } \\
\rho_{0} \phi_{o}=x \cdot p=x \frac{P}{\left(\frac{w l}{4}\right)} \quad x=0.1,0.2,0.3 \\
\stackrel{*}{J}=p \frac{w l}{4} U
\end{gathered}
$$

\section{EXPERIMENTAL PROCEDURE}

\section{A. Preparation of Specimens}

\section{1) Compaction}

Metal powder was compacted in a closed rectangular die (bore $15 \mathrm{~mm} X 10 \mathrm{~mm}$ ) using a 150 Ton hydraulic press at various recorded pressures. The compaction arrangement is shown in Fig. 1

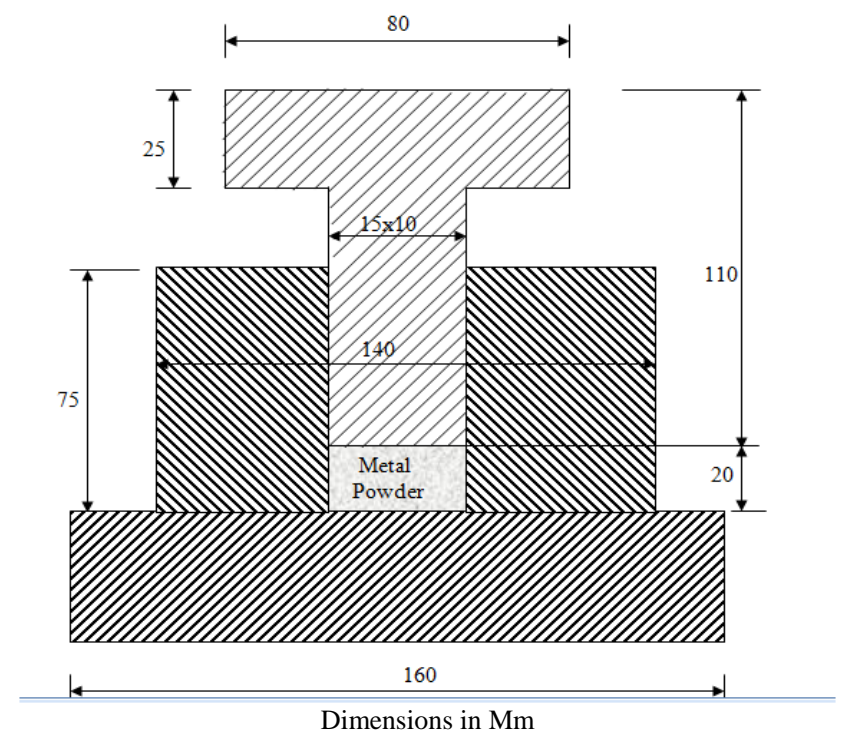

Fig. 1. Compaction of metal powder perform.

\section{2) Sintering}

Sintering of copper compacts was carried out at $850^{\circ} \mathrm{C}$ respectively for two hours.All sintering operations were carried out in a muffle type silicon carbide furnace capable of providing sintering temperature unto $1300^{\circ} \mathrm{C}$ with an accuracy of $\pm 5^{\circ} \mathrm{C}$. In order to minimize the non-uniformity of density distribution, the sintered compacts were re-pressed at the same compaction pressure in the same die. The specimens were resintered at the same temperature and time.

3) Machining

The specimens were made by machining the compacts to the desired dimensions. The surfaces of the specimens were polished with fine emery paper.

\section{B. Measurements.}

Experiments were conducted on a Universal Testing Machine using appropriate dies. The $\mathrm{Cu}$ metal powder preform of known relative density was placed inside the conical converging dies and was compressed at room temperature by applying the load. The compression was carried out in dry and lubricated conditions. Fine graphite powder was applied as lubricant. The following important measurements were made:

1) Increase in the relative density of the preform with increase in compressive load.

2) Variation of $p / \sigma_{0}$ (Relative forging pressure)of the perform with percentage reduction in height

3) Variation of $p / \sigma_{0}$ of the perform with change in density at $40 \%$ reduction in height

4) Increase in the relative density of the preform with increase in $p / \sigma_{0}$ (Relative forging pressure)

Electrolytic Copper powder of greater than $99 \%$ purity was used for preparation of test piece

TABLE I: PHYSICAL CHARACTERISTICS OF POWDER USED APPARENT

\begin{tabular}{|l|l|l|l|l|l|l|}
\multicolumn{7}{|c}{ DENSITY 2.60 G/CC TAP DENSITY 8.96G/C. } \\
\hline $\begin{array}{l}\text { Screen } \\
\text { Analysis } \\
\text { (micron) }\end{array}$ & +100 & $\begin{array}{l}-100 \\
+150\end{array}$ & $\begin{array}{l}-150 \\
+200\end{array}$ & $\begin{array}{l}-200 \\
+240\end{array}$ & $\begin{array}{l}-240 \\
+350\end{array}$ & -350 \\
\hline $\begin{array}{l}\% \\
\begin{array}{l}\text { Weight } \\
\text { Retained }\end{array}\end{array}$ & 0 & 35 & 15 & 14.5 & 20 & 14.5 \\
\hline
\end{tabular}

TABLE II: CHEMICAL ANALYSIS (WEIGHT \% OF POWDER).MAXIMUM LIMITS OF IMPURITIES-

\begin{tabular}{|c|c|}
\hline Copper & $99.80 \%$ \\
\hline Phosphorous & $<0.001 \%$ \\
\hline Iron & $<0.006 \%$ \\
\hline Silicon & $<0.002 \%$ \\
\hline
\end{tabular}

\section{RESUlt AND DisCUSSION}

In $\mathrm{Cu}$ metal powder forming process compaction (densification) and deformation happen simultaneously. Material flows mainly in the direction of punch movement, with a little lateral flow. As the density increases, lateral flow increases. In the final stage of deformation. let us assume following set of data

$$
\begin{gathered}
n=1,2 ; x=0.1,0.2,0.3 ; \\
\mu_{1}=0.3, \mu 2=0.3,0.35,0.4,0.45 ; \\
\rho=0.70,0.75,0.80,0.85,0.90,0.95
\end{gathered}
$$

Percentage reduction in height of the perform $=10 \%, 20 \%, 30 \%, 40 \%$.

We have considered different interfacial friction at the different surfaces.

Fig. 5 shows the variation of relative average forging pressure $(p / \lambda)$ with relative density of sintered preform by 
Upper bound method. The curves express the theoretical results at $40 \%$ reduction of the preform for different values of the coefficient of friction at upper and bottom surfaces, ignoring the deformation due to inertia factor by upper bound and equilibrium method. As relative density of the sintered perform increases, the required amount of relative forging pressure increases, experimental values of the relative forging pressure is nearly in close agreement with the theoretical values obtained by upper bound method.

Fig. 6, Fig. 7, Fig. 8, Fig. 10 and Fig. 11 shows the variation in relative average forging pressure $(p / \lambda)$ with percentage reduction in height of the metal powder perform at different initial relative density by Upper bound method at $n=1,2$ with different values of the coefficient of friction at upper and bottom surface considering the inertia factor These figures show the variation of relative density with average relative forging pressure.

Fig. 9 shows the variation of relative average forging pressure $(p / \lambda)$ with relative density of sintered preform by Upper bound method at $40 \%$ reduction.

Fig. 12, Fig. 13 shows variation in $\mathrm{p} / \lambda$ (Relative forging pressure) with $\%$ reduction in height of the metal powder perform by both the methods at $\rho=0.8 \mu_{1}=\mu_{2}$, We take different values of $\rho_{0} \phi_{0}$.

These Figures shows the theoretical compressive relative pressure versus percentage reduction. The curves express the theoretical results for a particular initial relative density of the preform and for various values of the coefficient of friction at upper and bottom surfaces. The compressive relative pressure is found to increase with increase in percentage reduction in height and the coefficient of friction, compressive relative pressure is also found to increase with increase in the value of $\rho_{0} \phi_{0}$.Inertia factor is also playing a vital role in deforming the workpiece. it is expected that the result of this paper will help the academician who are working in this field.

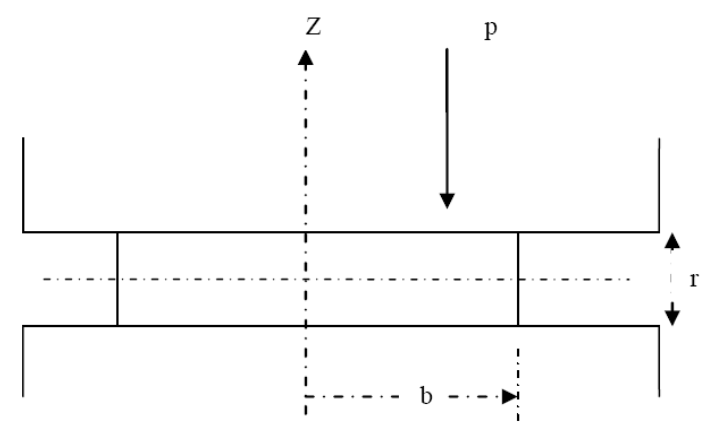

Fig. 2. Schematic diagram of disc (upper bound method).

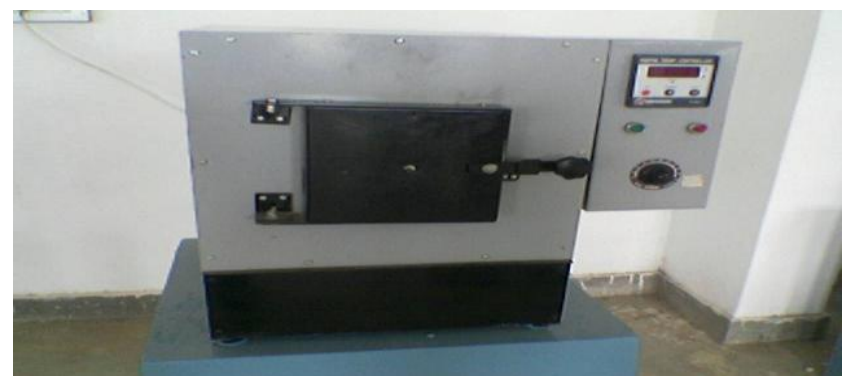

Fig. 3. Sintering furnace.

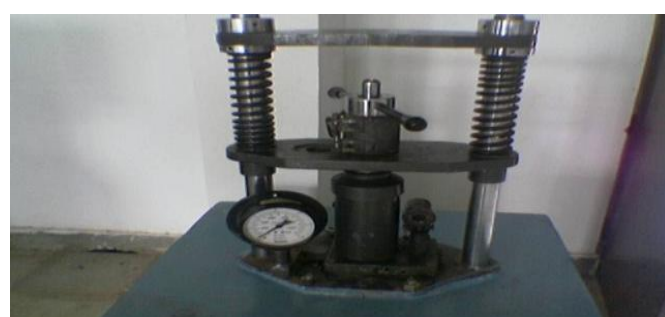

Fig. 4. Hydraulic press.

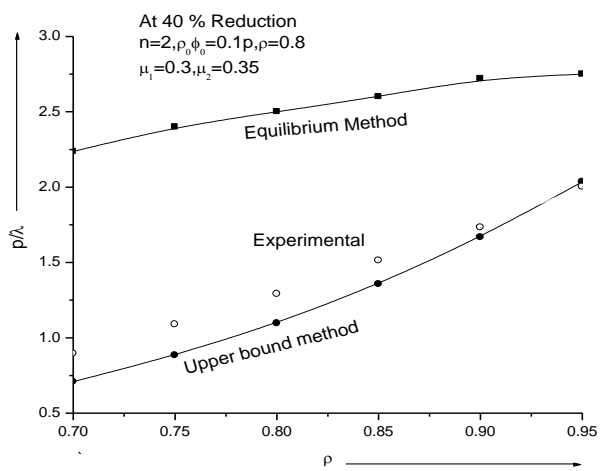

Fig. 5.

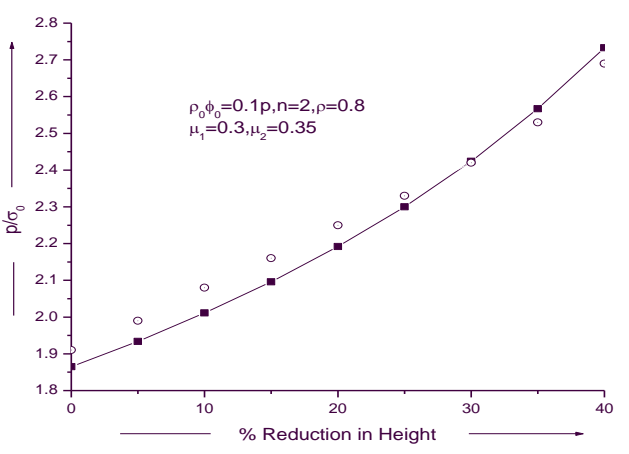

Fig. 6.

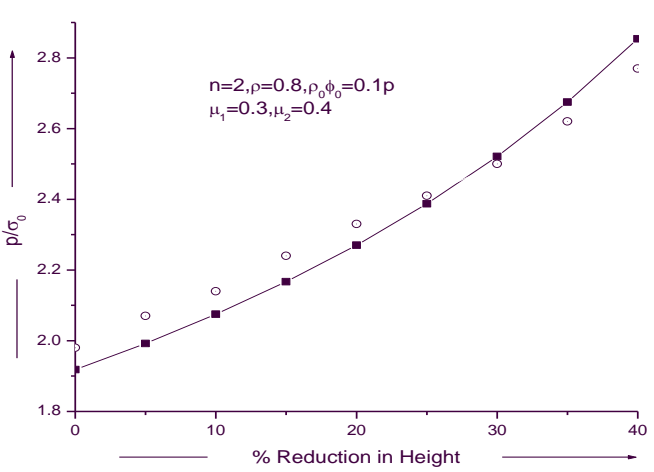

Fig. 7.

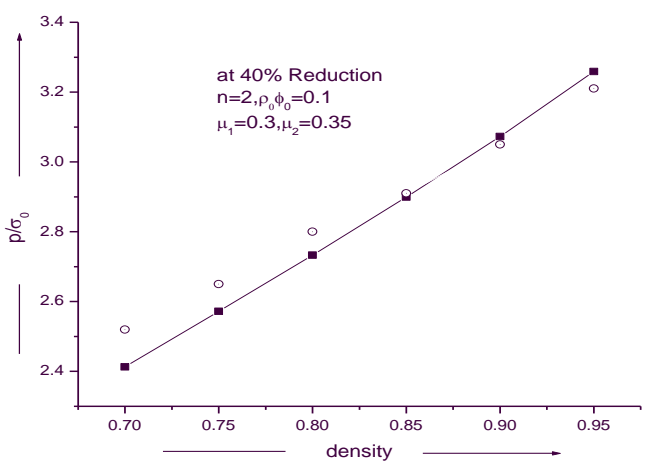

Fig. 8. 


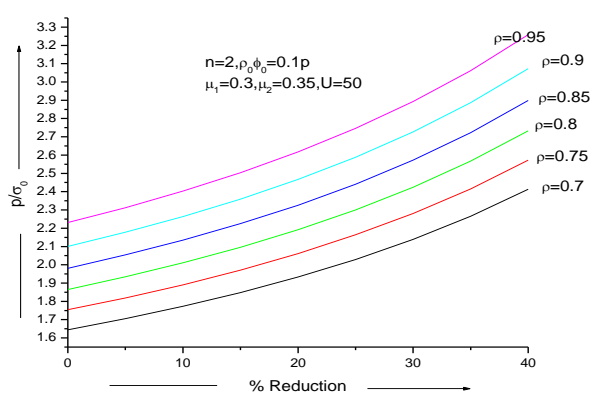

Fig. 9.

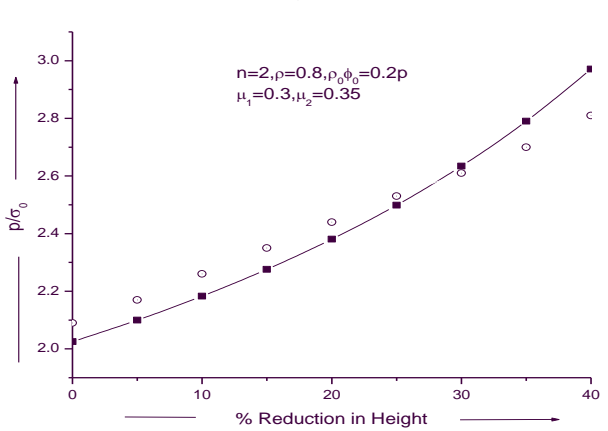

Fig. 10.

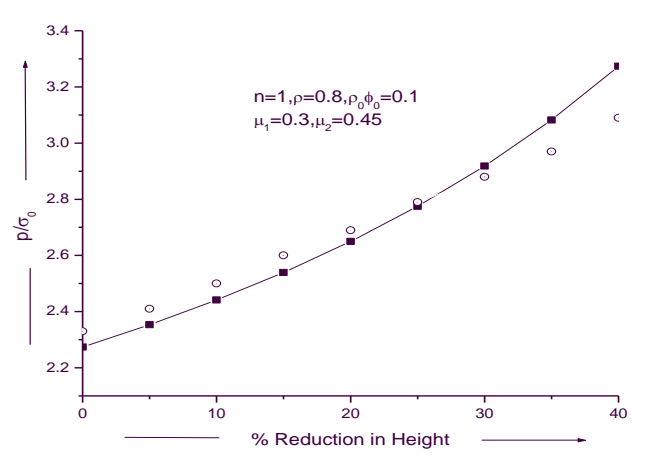

Fig. 11.

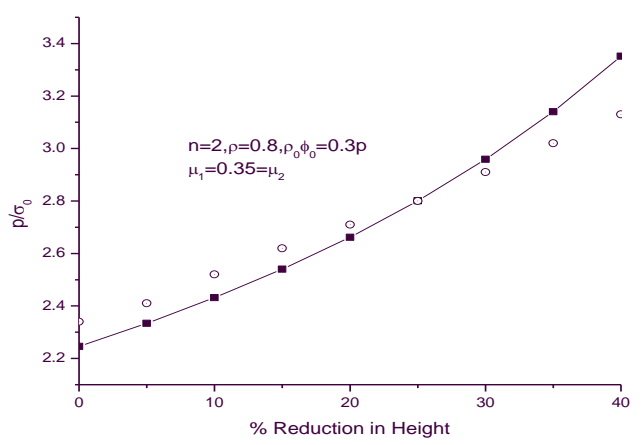

Fig. 12.

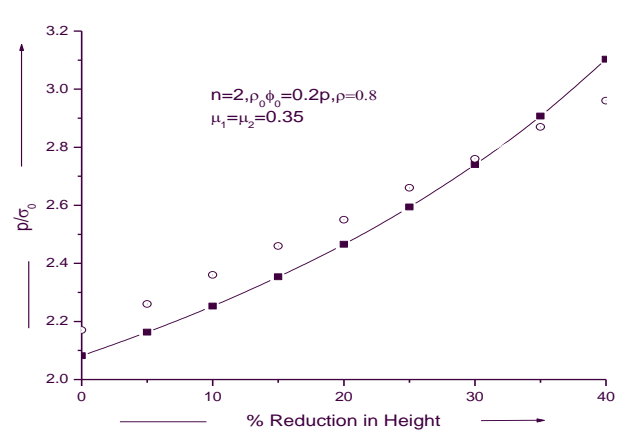

Fig. 13.

\section{CONCLUSION}

In powder forging, mass constancy is to be assumed. During forging of metal powder preforms it is seen that compaction and compression both take place simultaneously. Initially the closing of pores dominates the compression process.During forging of powder preforms, the mode of deformation is quite different from wrought materials and it is function of both density and hydrostatic stress The larger amount of applied load is utilized in densification and lesser amount is consumed for compression.

A composite interfacial friction law has been taken for studying the deformation characteristics of the sintered porous materials. The relative average forging pressure increases with increasing percentage reduction of height of the perform and coefficient of friction

\section{NOMENCLATURE}

$h=$ Instantaneous thickness of perform

$\mu_{1}=$ Coefficient of friction of upper surface

$\mu_{2}=$ Coefficient of friction of lower surface

$P=$ Die load , $\tau=$ Shear stress, $p=$ ram pressure

$\sigma_{0}=$ Yield stress of the non-work hardening matrix metal

$\mathbf{J}_{2}^{\prime}=$ Second invariant of deviatoric stress

$x, y, z=$ Cartisian co-ordinates,

$n=$ A constant quantity

$\rho_{0}=$ A dimensional ratio $\left(=\rho_{\mathrm{r}} / \rho_{*}\right)$,

$\phi_{0}=$ specific cohesion of a contact surface

$k=$ Constant equal to 2 in yield criterion

$\rho_{*}, \rho_{r}=$ Densities of apparent and real contact

$\eta=$ Constant and a function of $\rho$ only

$\rho=$ Relative density of the perform

$\dot{\varepsilon}_{r}, \dot{\varepsilon}_{\theta}, \dot{\varepsilon}_{z}=$ Principal strain increment

\section{ACKNOWLEDGMENT}

Authors acknowledge Department of Mathematics BRCM College of Engineering \& Tech. Bahal and Deenbandhu Chottu Ram University of Science \& Tech.(DCRUST) Murthal Haryana India for supporting this work

\section{REFERENCES}

[1] P. F. Thomson, "Densification of sintered metal compacts by cold deformation," J. Mech. Working Tech. vol. 13, no. 2, pp. 219227,1986

[2] "Cost savings win the day for PM parts," Metal Powder Report, vol. 56, no. 7 - 8, pp. $10-12,2001$

[3] A. K. Jha and S. Kumar, "Production of sinter- forged components," $J$. Mater Process. Tech. vol. 41, pp. 143-169, 1994

[4] S. Singh and A. K .Jha, "Sintered performs adds better value to aerospace components," J. Aerospace Engg. I.E. vol. 1, no. 82, pp. 1-6, 2001

[5] E. Ilia, K. Tutton, and M. O'Neill, "Forging a way towards a better mix of PM automotive steels," Metal Powder Report vol. 60, no. 3, pp. 38-44,2005

[6] A. K. Jha and S. Kumar, "Forging of metal powder performs, Int." J. Mach. Tool Design Res. vol. 23, no. 210, 1996

[7] L. M. M. Alvesa, P. A. F. Martinsa, and J. M. C. Rodrigues, "A new yield function for porous materials," J. Mater. Process. Tech. vol. 179 , no. 1-3, pp. 36-43, 2006

[8] A. K. Jha and S. Kumar, "Deformation characteristics and fracturing of sintered copper powder strips during cold forging," J. Mech. Work 
Technol. vol. 16, no. 145, 1988. Sci. Technol. vol. 22, no. 2, pp. 45 , 1978

[9] S. Malayappan and G. Esakkimuthu, "Barreling of aluminium solid cylinders during cold upsetting with differential frictional conditions at the faces," Int. J. Adv. Manuf. Tech. vol. 29, pp 41-48, 2006

[10] B. W. Rooks, "The effect of die temperature on metal flow and die wear during high speed hot forging," 15th Int. MTDR conference held in Birmingham 18- 20 September 1974, pp. 487.

[11] T. Tabata, S. Masaki, and K. Hosokawa, Int. J. Powder Metal, Powder technol, vol. 16, no. 149, 1980

[12] P. Kumar, R. K. Ranjan, and R. Kumar ARPN Journal of Engineering and Applied Sciences vol. 6, no. 6 pp. 83-93, 2011

[13] B. Aksakal, F. H. Osman, and A. N. Bramley Journal of Materials processing Technology vol. 71, pp. 215-223, Elsevier 1997

[14] P. Kumar, R. K. Ranjan, and R. Kumar Int. Journal of Applied Sciences and Tech Research Excellence vol. 1, no. 1, pp. 24-28, 2011

[15] L. M. M. Alvesa, P. A. F. Martinsa, and J. M. C. Rodrigues, "A new yield function for porous materials," J. Mater. Process. Tech. vol. 179, no. 1-3, pp. 36-43, 2006

[16] S. Malayappan and G. Esakkimuthu, "Barreling of aluminium solid cylinders during cold upsetting with differential frictional conditions at the faces," Int. J. Adv. Manuf. Tech. vol. 29, pp. 41-48, 2006

[17] K. Katuku, A. Koursaris, and I. Sigalas, Journal of Material Processing Technology vol. 209, 2009

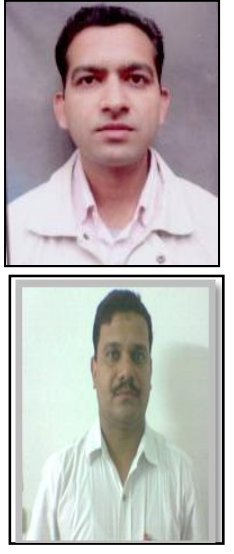

Parveen Kumar is working as Assistant Professor (Mathematics) in Department of Applied Sciences BRCM College of Engineering and Technology Bahal (Bhiwani)Haryana INDIA. He did his postgraduation in Mathematics from GJU Haryana and M Phill from Algappa University Tamilnadu INDIA. His research theme is Mathematical modeling of sinter metal forming .

Dr. R. K. Ranjan received his Ph.D from Birla Institute of Technology, India in 2005. He did his M. Tech. in Production specialization from Institute of Technology, BHU, Varanasi, UP, India in 1997. At present he is Professor. \& Head, ME Department at Gyan Ganga ITS, Jabalpur, India. There are more than 50 research papers in his credit. He has completed one research project sponsored by Dept. of Science and Technology, India. Two Projects funded by AICTE, New Delhi, India are going on under his supervision.

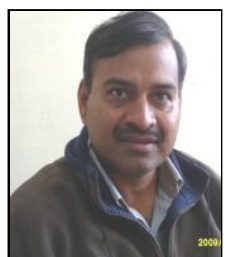

Dr. Rajive Kumar did his Ph.D. in 1990 from Indian Institute of Technology, Delhi, India and have more than twenty years research experience in the field of Numerical Solutions of Non-linearly Damped Oscillators and Software Engineering. At present he is Professor in Mathematics DCRUST INDIA He has published more than 25 research papers in international \& national journals and participated in various national and international conferences. 